Article

\title{
Feasibility Assessment of Using Power Plant Waste Heat in Large Scale Horticulture Facility Energy Supply Systems
}

\author{
Min Gyung Yu and Yujin Nam * \\ Department of Architectural Engineering, Pusan National University, 2 Busandaehak-ro 63, Geomjeong-gu, \\ Busan 609-735, Korea; min324806@gmail.com \\ * Correspondence: namyujin@pusan.ac.kr; Tel.: +82-51-510-7652; Fax: +82-51-514-2230 \\ Academic Editor: Hossam A. Gabbar \\ Received: 3 September 2015; Accepted: 29 January 2016; Published: 18 February 2016
}

\begin{abstract}
Recently, the Korean government has been carrying out projects to construct several large scale horticulture facilities. However, it is difficult for an energy supply to operate stably and economically with only a conventional fossil fuel boiler system. For this reason, several unused energy sources have become attractive and it was found that power plant waste heat has the greatest potential for application in this scenario. In this study, we performed a feasibility assessment of power plant waste heat as an energy source for horticulture facilities. As a result, it was confirmed that there was a sufficient amount of energy potential for the use of waste heat to supply energy to the assumed area. In Dangjin, an horticultural area of 500 ha could be constructed by utilizing $20 \%$ of the energy reserves. In Hadong, a horticulture facility can be set up to be 260 ha with $7.4 \%$ of the energy reserves. In Youngdong, an assumed area of 65 ha could be built utilizing about $19 \%$ of the energy reserves. Furthermore, the payback period was calculated in order to evaluate the economic feasibility compared with a conventional system. The initial investment costs can be recovered by the approximately $83 \%$ reduction in the annual operating costs.
\end{abstract}

Keywords: horticulture; power plant waste heat; energy reserves; feasibility

\section{Introduction}

\subsection{Background}

As industrial development and greenhouse gas emissions have caused global climate changes, countries around the world have been searching for detailed measures and long term solutions to reduce environmental damage. South Korea, one of the world's 10 major energy consuming countries, has been promoting national development strategies for green and sustainable economic growth. As a part of the energy policy for green growth, the Korean government has shown recent interest in the energy independence of rural areas by replacing existing energy sources with renewable energy sources. Renewable energy supply in rural areas has been mainly achieved by supporting the use of geothermal heat pump systems and wood pellet boilers. The government has also been creating several large scale protected horticulture estates of more than 100 ha in size by utilizing reclaimed land, which is a promising measure for national interests through the export of high value crops. Therefore, a policy of energy independence in rural areas is essential for the agricultural future; a need has therefore arisen to develop energy systems using natural energy resources in rural areas [1,2].

Moreover, it is essential for large scale protected horticulture to consider stable heat source supply and feasibility when designing an energy source system. If it is designed to satisfy a peak load in general, there is a risk of overdesign. In addition, the optimum system capacity needs to be 
designed considering energy efficiency, thermal storage system, operating schedule, pipe network, energy source system arrangement and so on [3]. Alternative heat sources need to be especially considered, since a conventional fossil fuel system incurs high heating costs. Hence, an increase in the use of renewable energy sources, such as geothermal, biomass, solar and power plant waste heat has been observed [4-6]. Chau et al. [7] studied the economic feasibility of using wood biomass for greenhouse heating applications and the results indicate that for average ( $7.5 \mathrm{ha})$ or large (15 ha) scale greenhouses it is economical to install weed pellet boilers. Benli et al. [8,9] analyzed the performance of a ground source heat pump system with latent heat storage in greenhouses and figured out that the total system coefficient of performance was determined to be 2-3.5. Esen et al. [10] evaluated a biogas, solar and ground source heat pump greenhouse heating system (BSGSHPGHS) and the performed experiments successfully proved that renewable energy sources should be utilized in greenhouses. Among these sources, power plant waste heat has gained attention for its potential applications in protected horticulture because it is generated in the coastal areas near rural communities. In addition, Park et al. [4] investigated unused energy reserves in Korea for utilization as energy sources in rural communities and they found that the power plant waste heat has the greatest potential and reserves.

Power plant waste heat is generated during the power production process of a plant and typically discarded into the sea after being absorbed in the cooling water. When considering the efficiency of a power plant is about $40 \%$, the remaining $60 \%$ of the power is thus discarded as waste heat. In Korea, about 55 billion tons of thermal effluent are released annually, which is equal to about 452 TWh if converted to energy. This implies that it is possible to reduce energy costs by using this energy instead of fossil fuel. However, power plant waste heat has seldom been applied as an energy source in horticulture, so a great deal of this energy has been wasted [11,12].

On the other hand, power plant waste heat has mainly been utilized as an energy source system for district heating. Therefore, many studies have been developed to effectively transfer the heat source from power plants for district heating. Dalla Rosa et al. $[13,14]$ discussed the influence of the temperature and conductivity of soil to carry out a network design model for low energy and to reduce heat losses. To select a better design, Tol et al. [15] compared the heat losses and temperature drops of various network layouts and substations. Xiang-Li [16] developed an optimal pipe network using a genetic algorithm. With this method, they attempted to avoid the unbalance of the system, enhance the efficiency and reduce the costs compared with a conventional system. Yildirim [17] conducted a case study for a piping network design considering the cost and pressure loss of various pipe materials. Moreover, Ivner et al. [18] analyzed the effect of a system using industrial excess heat on greenhouse gas emissions in different future scenarios. Unlike many studies conducted extensively on district heating, little attention has been given to the horticulture industry.

Recently, several countries have been applying power plant waste heat for horticulture on a trial basis. In France, the Dampierre nuclear power plant has been supplying its waste heat as the only heat source to a large scale horticulture estate of 150 ha in size [19]. In light of the success of this project, many studies have been conducted on applying this approach in Korea [12,20-22]. For a potential application, Lee et al. $[20,21]$ implemented a performance analysis on the system according to the distance from the heat source and pipe material to effectively utilize the power plant waste heat. However, little information is available on the feasibility of considering power plant waste heat energy reserves for large scale protected horticulture.

Considering this background, this study uses a dynamic energy simulation to provide a quantitative feasibility evaluation of the utilization of power plant waste heat as an energy source in protected horticulture. Heating energy consumption was analyzed and the feasibility of using power plant waste heat was examined compared with the conventional system.

\subsection{Methods and Scope}

In this study, the research was performed according to the following procedure: first, some basic data of 30 power plants in Korea were gathered, including information on thermal effluent outflow 
capacity per year and temperature difference [11,12]. Using these data, the energy reserves and available heating capacity of each power plant were derived. Then, Dangin, Hadong, and Youngdong were selected as case study areas and the greenhouse heating energy consumption was calculated in each area. From the analysis, possible horticulture scale was dealt with the power plant waste heat energy reserves and the nearby farmland. Finally, the feasibility of the heat pump system using waste heat energy source was discussed compared with the conventional tax-free diesel boiler.

\section{Energy Reserves of Power Plant Waste Heat}

\subsection{Overview of Power Plant Waste Heat}

In South Korea, there are almost 30 thermal and nuclear power plants, so about 55 billion tons of power plant thermal effluent is wasted per year through the absorption of the waste heat generated from the power plant $[11,12]$. However, the energy reserves differ between the power plants located in different regions due to the difference in the efficiency of power generation and waste water capacity as well as the temperature difference. Therefore, it is important to conduct quantitative evaluations on the conditions of each power plant.

In this section, we investigate the power plant thermal effluent outflow capacity and temperature difference of the cooling water using data from the Korean Ministry of Maritime Affairs and Fisheries, as shown in Table $1[11,12,23]$. The temperature difference between power plants was around $7^{\circ} \mathrm{C}$, but the amount of thermal effluent outflow at the nuclear power plant was relatively larger than that at the thermal power plants.

Table 1. Emission situation of power plant thermal effluent [11,12].

\begin{tabular}{|c|c|c|c|c|c|}
\hline \multirow{2}{*}{ Plant } & \multicolumn{2}{|c|}{ Thermal Effluent } & \multirow{2}{*}{ Plant } & \multicolumn{2}{|c|}{ Thermal Effluent } \\
\hline & Capacity (106 ton/Year) & $\Delta \mathrm{t}\left({ }^{\circ} \mathrm{C}\right)$ & & Capacity (106 ton/Year) & $\Delta \mathrm{t}\left({ }^{\circ} \mathrm{C}\right)$ \\
\hline West Incheon & 4.6 & 6.4 & Youngnam & 2.3 & $8 \sim 8.3$ \\
\hline Incheon & 2.2 & $7 \sim 10.2$ & Wolseung & 47.2 & 8.2 \\
\hline New Incheon & 8.7 & 7 & Posco, Pohang & 7.0 & $7 \sim 8$ \\
\hline Posco Incheon & 1.9 & $10 \sim 13.5$ & Uljin & 60.8 & 7.2 \\
\hline Youngheung & 17.4 & 6.4 & Donghae & 3.9 & 7.2 \\
\hline Pyeongtaek & 5.9 & 10 & Youngdong & 1.7 & 9.2 \\
\hline gs Bugok & 1.8 & 7 & Yeosu & 2.3 & 6.4 9.4 \\
\hline Dangiin & 20.5 & $6.4 \sim 6.8$ & Honam & 6.3 & 8.8 \\
\hline Taean & 26.2 & 7.7 & Gwangyang & 12.6 & $5 \sim 6$ \\
\hline Boryung & 39.1 & $6.4 \sim 7$ & Yulchon & 2.4 & 7 \\
\hline Seocheon & 2.4 & 9.4 & $\begin{array}{c}\text { Posco, } \\
\text { Gwangyang }\end{array}$ & 8.6 & $7 \sim 8$ \\
\hline Younggwang & 74.6 & 7.4 & Hadong & 24.3 & 6.4 \\
\hline Pusan & 7.5 & 8.2 & Samcheonpo & 27.4 & $6.4 \sim 9.5$ \\
\hline Geori & 44.6 & 4.7 & Jeju & 2.1 & 7 \\
\hline Ulsan & 13.4 & $7 \sim 10$ & South Jeju & 0.3 & 7 \\
\hline
\end{tabular}

\subsection{Calculation of Power Plant Waste Heat Energy Reserves}

For utilizing power plant waste heat as a heat source, the energy reserves need to be calculated in order to carry out a quantitative analysis. Energy reserves can be estimated for available capacity in terms of the heat source, and the basic formula of thermodynamics can be applied shown below $[4,6]$ :

$$
E=Q \times C \times \Delta t
$$

where $E$ : Energy reserves (Tcal/year), Q: flow rate (ton), $C$ : specific heat $\left(\mathrm{kcal} / \mathrm{kg} \cdot{ }^{\circ} \mathrm{C}\right), \Delta t$ : temperature difference $\left({ }^{\circ} \mathrm{C}\right)$.

From the calculation result, the total energy reserve in Korea is determined to be $341.914 \mathrm{Tal} /$ year. However, if the energy is used for a horticultural heat source, it should be investigated from power plants located near rural communities. Moreover, if waste heat is used for a cooling source, the discharged water temperature will increase further because it has already discharged at a higher state. Therefore, the available heating capacity was determined without cooling and it was assumed that the 
heating period is 5 months from November to March. In addition, the efficiency associated with the piping loss was applied to the calculation formula, which is as follows:

$$
E_{H}=k \times E
$$

where $E_{H}$ : Heating available capacity (Tcal/year), $k$ : efficiency associated with piping loss, $E$ : Energy reserves (Tcal/year).

Table 2 shows the calculation results, which indicate that the energy reserves differ in terms of the thermal effluent outflow capacity and temperature difference of each power plant. Among these results, nuclear power plants have a significantly greater amount of energy reserves than thermal power plants. This trend is the same as that observed for thermal effluent outflow capacity. However, only the thermal power plants were considered due to the radioactive contamination problems of nuclear power plants.

Table 2. Energy reserves and heating available capacity of each power plant.

\begin{tabular}{|c|c|c|c|c|c|}
\hline Plant & $\begin{array}{c}\text { Reserves } \\
\text { (Tcal/Year) }\end{array}$ & $\begin{array}{l}\text { Heating Available } \\
\text { Capacity } \\
\text { (Tcal/Year) }\end{array}$ & Plant & $\begin{array}{l}\text { Reserves } \\
\text { (Tcal/Year) }\end{array}$ & $\begin{array}{c}\text { Heating Available } \\
\text { Capacity } \\
\text { (Tcal/Year) }\end{array}$ \\
\hline West Incheon & 2937 & 1020 & Youngnam & 1870 & 649 \\
\hline Incheon & 1887 & 655 & Wolseung & 38,612 & 13,407 \\
\hline New Incheon & 6076 & 2110 & Posco,Pohang & 5238 & 1819 \\
\hline Posco Incheon & 2227 & 773 & Uljin & 43,672 & 15,164 \\
\hline Youngheung & 11,109 & 3857 & Donghae & 2801 & 973 \\
\hline Pyeongtaek & 5886 & 2044 & Youngdong & 1560 & 542 \\
\hline gs Bugok & 1257 & 436 & Yeosu & 1813 & 629 \\
\hline Dangin & 13,498 & 4687 & Honam & 5531 & 1920 \\
\hline Taean & 20,126 & 6988 & Gwangyang & 6914 & 2401 \\
\hline Boryung & 26,135 & 9075 & Yulchon & 1676 & 582 \\
\hline Seocheon & 2251 & 781 & Posco, Gwangyang & 6435 & 2234 \\
\hline Younggwang & 55,073 & 19,122 & Hadong & 15,515 & 5387 \\
\hline Pusan & 6135 & 2130 & Samcheonpo & 21,731 & 7546 \\
\hline Geori & 20,912 & 7261 & Jeju & 1467 & 509 \\
\hline Ulsan & 11,363 & 3945 & South Jeju & 210 & 73 \\
\hline
\end{tabular}

\section{Evaluation Methods}

\subsection{Case Study Area}

In this paper, three different power plants in Korea (the Dangjin power plant located in Incheon, the Hadong power plant located in Gyeongnam, and the Youngdong power plant located in Kangnung) were chosen to examine whether constructing large scale horticulture systems is feasible under different conditions. Figure 1 shows the waste heat energy reserves of each power plant and the case study areas showing the nearby farmland.

As shown in Figure 1, the selected power plants are located on different coasts and have different energy reserves. In addition, it was checked whether the areas included any large scale farmland near the power plants. The Dangjin power plant, located on the west coast, has $4000 \mathrm{MW}$ of power generation capacity and discharges about 20.5 billion tons of thermal effluent per year, which means that the potential energy reserve for utilization is 13,498 Tcal/year. In addition, it was confirmed that more than 1300 ha of large-scale reclaimed land is available for agriculture located about $1.5 \mathrm{~km}$ from the power plant. The Hadong power plant located on the southern coast has a power generation capacity of $4000 \mathrm{MW}$ and a thermal effluent of about 24.3 billion tons is discharged every year. In other words, it discharges 15,515 Tcal/year of waste energy and has significant potential for the construction of more than 260 ha of agricultural reclaimed land within $2 \mathrm{~km}$ of the power plant. The Youngdong power plant located on the East coast has $325 \mathrm{MW}$ of power generation capacity and discharges 1.7 billion tons of thermal effluent which means 1560 Tcal per year. It was confirmed that about 65 ha of farmland is situated $0.5 \mathrm{~km}$ from the power plant and 190 ha farmland is situated $3 \mathrm{~km}$ from the power plant. Considering this, we secured enough land near the power plant for analysis in this study. 


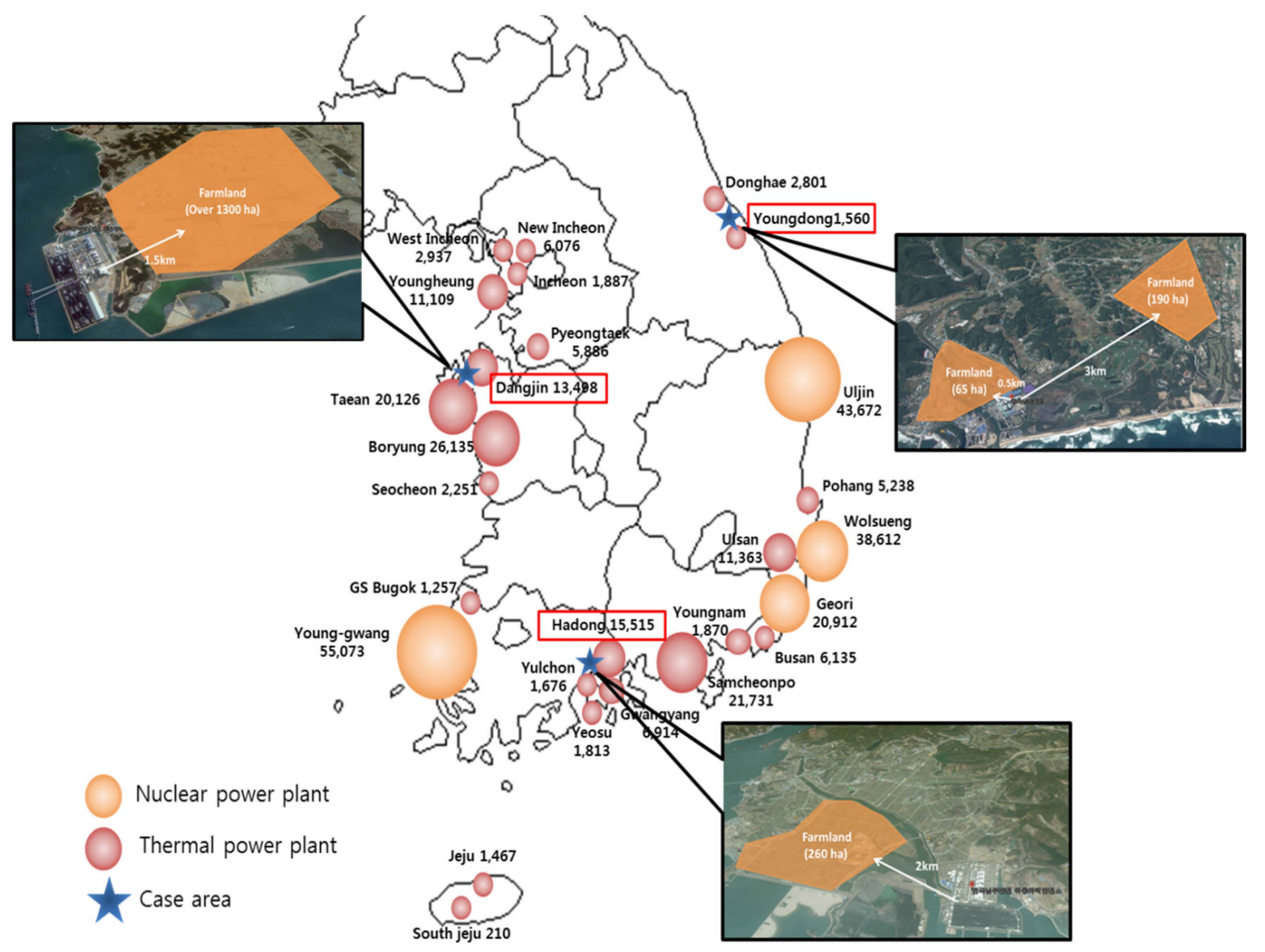

Figure 1. Case study areas with energy reserves (Tcal/year).

In this study, 500 ha of large-scale agricultural land were assumed to be used for a horticulture estate in the case of Dangjin and 260 ha of horticulture estate is used in the case of Hadong. In the case of the Youngdong power plant, 65 ha of farmland were considered as horticulture estate located within $0.5 \mathrm{~km}$ of the power plant. These cases were selected to determine the influence in each region of energy reserves and available nearby farmland.

\subsection{Description of Total Framework}

Figure 2 shows the total analysis model of this study with the heating system using power plant waste heat. The system is configured as follows: first, a heat recovery device is installed in the thermal effluent tank of each power plant. The heat recovery water is then delivered to the heat pump through the pipes, which increases the water temperature to $55 \sim 60^{\circ} \mathrm{C}$ to store in a heated storage tank. The stored water is used for greenhouse heating with $40 \sim 45^{\circ} \mathrm{C}$ through a fan coil. During the operation, electric energy is used in each component of this system such as the pipes, heat pump, circulating pump and so on. It is therefore possible to perform an economic evaluation. Furthermore, the heat loss through the pipeline was evaluated, so that it was recognized how much energy can be used in the load side with energy reserves of heat source side. However, the basic system diagram is insufficient here and another pipeline needs to be designed and analyzed considering the transmitting power and heat loss of the pipe. Hence, a possible pipeline design was assumed as shown in Figure 3, which is designed based on the actual distribution diagram conducted in Korea [12]. In addition, the diameter and flow rate of the pipe that transports heat to the heat pump and to the greenhouse were calculated and analyzed considering each load analysis. 


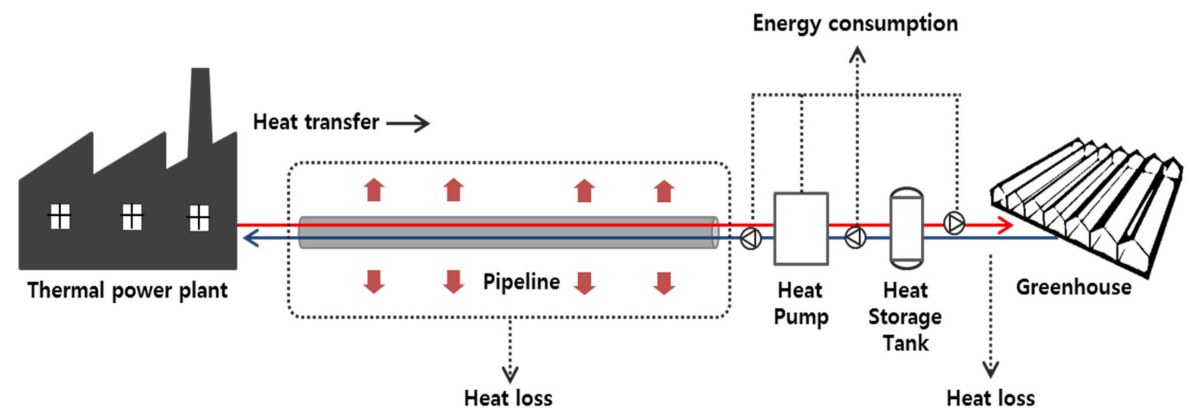

Figure 2. Structure of the analysis model and system diagram.

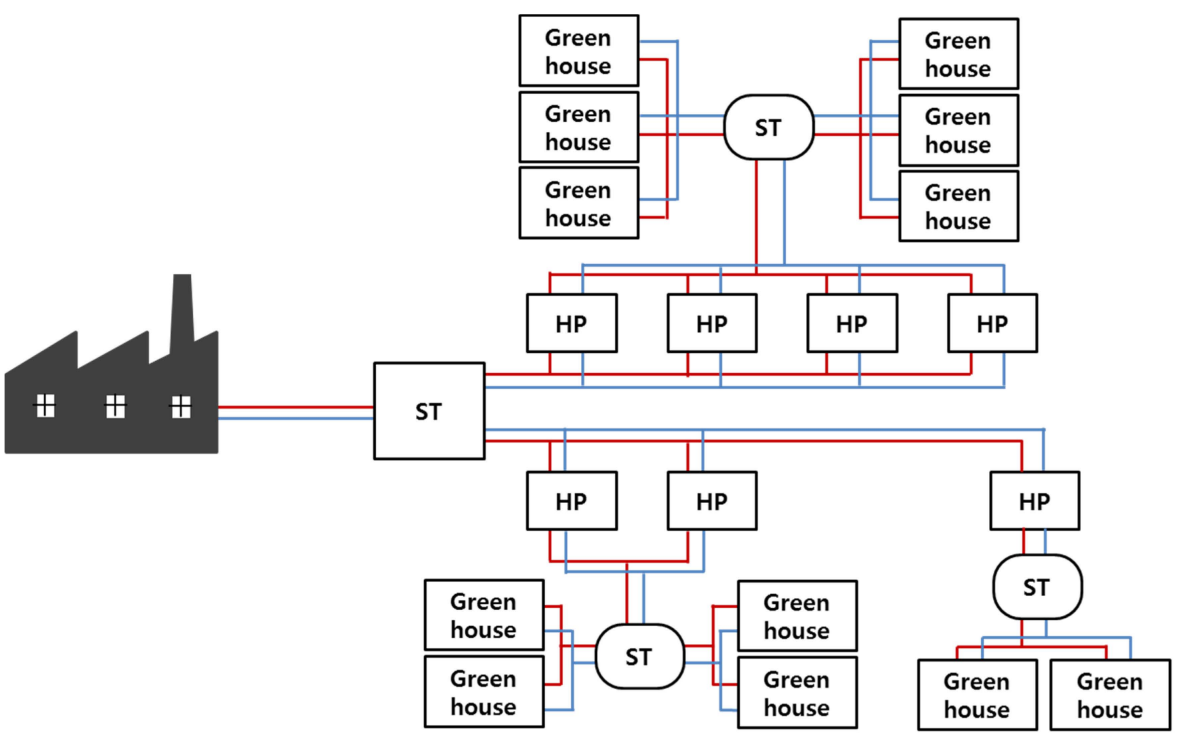

Figure 3. Possible design of pipeline.

\subsection{Description of Load Analysis Model}

To ensure a quantitative energy analysis, the energy load pattern analysis should be carried out using dynamic energy simulation. Therefore, the greenhouse unit model was utilized which is previously demonstrated [3,24], as shown in Figure 4. The greenhouse model is a domestic standard greenhouse [25] with a covering material of glass with a U-Value set to $5.29 \mathrm{~W} / \mathrm{m}^{2} \cdot \mathrm{K}$. Table 3 indicates more information about the load analysis conditions. The simulation period is from November to March, reflecting the greenhouse heating period and daily heating time scheduled from 17:00 to 8:00 of the next day. In order to set the greenhouse thermal environmental condition [26], we chose paprika, a typical high-value crop, and conducted simulation analysis using the weather data of the previously selected areas.

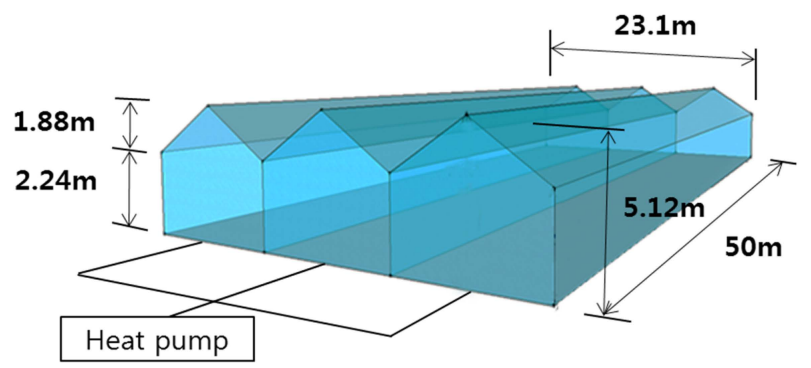

Figure 4. Greenhouse unit model. 
Table 3. Simulation conditions.

\begin{tabular}{cc}
\hline & Fixed Value \\
\hline Simulation period & January, February, March, November, December \\
Heating schedule & $17: 00 \sim 08: 00$ \\
Agricultural crops & Paprika \\
Set heating temperature & $18^{\circ} \mathrm{C}$ \\
Outer wall & Glass $\left(5.29 \mathrm{~W} / \mathrm{m}^{2} \cdot \mathrm{K}\right)$ \\
Ventilation & 1.57 times $/ \mathrm{h}$ \\
\hline
\end{tabular}

\subsection{Evaluation Method of Heat Loss through Pipeline}

In this study, heat loss through the pipeline was considered to examine the temperature drop of the heat source and to efficiently use the energy from the heat source side. The heat loss occurs through the surface of the pipe during the transmission, which is from the heat source side to the load side. The heat loss at the pipeline could differ in terms of distance, pipe properties and circulation water conditions. Especially, if the significant length of the pipeline from the power plant to the horticulture area was considered, the large amount of heat loss needs to be evaluated. Various studies related to the heat loss of pipelines have been conducted. Lee $[20,21]$ carried out research regarding the transport piping from heat sources for horticulture. Referring to this study, the calculation of the heat transfer was conducted between the underground pipe and the surrounding soils. In addition, it was assumed that the heat transfer between the circulation water and the soil is equal to the heat loss, as shown in the following Equation (3).

In this study, the heat loss of pipeline was examined utilizing this formula. The method is described in detail in Lee's research $[20,21]$ and is thus omitted in this paper. The temperature drop was followed by the heat loss of the pipeline and the outlet fluid temperature was calculated using Equation (3):

$$
U_{t} \mathrm{dy}\left[T_{w}(\mathrm{y})-T_{s o i l}\right]=-m_{w} C_{w}\left[d T_{w}(y)\right]
$$

where $U_{t}$ : overall heat transfer coefficient of the whole pipe $\left(\mathrm{W} / \mathrm{m} \cdot{ }^{\circ} \mathrm{C}\right), T_{w}$ : Fluid temperature $\left({ }^{\circ} \mathrm{C}\right)$, $T_{\text {soil }}$ : Ground temperature $\left({ }^{\circ} \mathrm{C}\right), m_{w}$ : mass flow rate of fluid through pipe $(\mathrm{kg} / \mathrm{s}), C_{w}$ : Specific heat of water $\left(\mathrm{J} / \mathrm{kg} \cdot{ }^{\circ} \mathrm{C}\right)$.

Furthermore, it was assumed that the ground temperature of each case study area followed the data from the Korean Institute of Energy Research (KIER) [27]. Referring to the data, the ground temperatures are $14.6{ }^{\circ} \mathrm{C}$ in Dangjin, $15.8^{\circ} \mathrm{C}$ in Hadong, and $13.7^{\circ} \mathrm{C}$ in Youngdong. In addition, the ingoing fluid temperature was assumed to be $20^{\circ} \mathrm{C}$ according to the temperature of the power plant thermal effluent in winter [12].

\subsection{Calculation Method of Energy Consumption}

Total energy consumption was calculated with the required heating energy consumption for the greenhouse and pumping power for heat source transmission. The required energy consumption for the greenhouse can be calculated according to the heating load, which is the supply amount of heat required for heating. In other words, the heat capacity required to operate heating equipment needs to be determined. Therefore, the energy consumption of the heating system was estimated in terms of the required calories based on the load analysis. In addition, it was assumed that the waste heat system utilizes a heat pump with a heating performance of COP 3.6 following the minimum performance criteria of renewable energy equipment examination (GT101) to calculate electricity consumption.

On the other hand, in order to calculate the pumping power, both sides of the pipes connecting the heat recovery tank to the heat pump and heat pump to fan coil unit need to be considered. In each 
section, the pumping power for hot water delivery is needed, and this can be calculated using the following Equation (4) [28]:

$$
P_{P M}=\frac{g \times G_{S} \times H}{\eta_{p}} \times 1000^{-2} \times 60^{2}
$$

where, $P_{P M}$ : pumping energy consumption $(\mathrm{MJ} / \mathrm{h})$, g: gravitational acceleration $\left(\mathrm{m} / \mathrm{s}^{2}\right), G_{S}$ : media flux $(\mathrm{kg} / \mathrm{s}), \mathrm{H}$ : lifting height $(\mathrm{m}), \eta_{p}$ : pump efficiency ratio $(0.75)$.

To apply Equation (4), the pipe diameter and flow rate in each load side and heat source side were first determined by the required heat capacity and according to the commercial brochure [29]. Therefore, the pipe in the heat source side was $65 \mathrm{~A}$ in diameter with an $8.9 \mathrm{~kg} / \mathrm{s}$ flow rate. In the case of the load side, the pipe was $50 \mathrm{~A}$ in diameter with a $5.2 \mathrm{~kg} / \mathrm{s}$ flow rate. In addition, the heat transport pipe material is assumed to be HDPE with a thermal conductivity is $0.335 \mathrm{~W} / \mathrm{mK}$. The length of the heat source side pipe is the same as that for the case study area.

\section{Analysis Results}

\subsection{Heating Load Analysis}

Table 4 and Figures 5 and 6 show the greenhouse heating load analysis results in each case area. The Dangjin power plant is located in Incheon, where the average temperature during winter is the coldest. From the load analysis, the peak load was determined to be $190 \mathrm{~W} / \mathrm{m}^{2}$ in January and the annual total heating load per square meter was $218 \mathrm{kWh}$. The Youngdong power plant is located in Kangnung, which is a warmer area as the mountains block the winter monsoon and the influence of the ocean current. In this area, the peak load was calculated as $177 \mathrm{~W} / \mathrm{m}^{2}$ in January and the annual heating load per square meter was $188 \mathrm{kWh}$. The Hadong power plant is located in Gyeongnam, where the average temperature is the warmest among them. As a result, the peak load was determined to be $166 \mathrm{~W} / \mathrm{m}^{2}$ and the annual heating load per square meter was $179 \mathrm{kWh}$. The load results of the Dangjin power plant were the highest because the ambient temperature in Incheon was the lowest.

Table 4. Heating load of each case area $\left(\mathrm{kWh} / \mathrm{m}^{2}\right)$.

\begin{tabular}{ccccccc}
\hline Location & January & February & March & November & December & Peak $\left(\mathbf{W} / \mathbf{m}^{\mathbf{2}}\right)$ \\
\hline Dangjin & 58 & 48 & 31 & 30 & 51 & 190 \\
Hadong & 48 & 40 & 26 & 24 & 41 & 166 \\
Youngdong & 50 & 43 & 28 & 25 & 42 & 177 \\
\hline
\end{tabular}

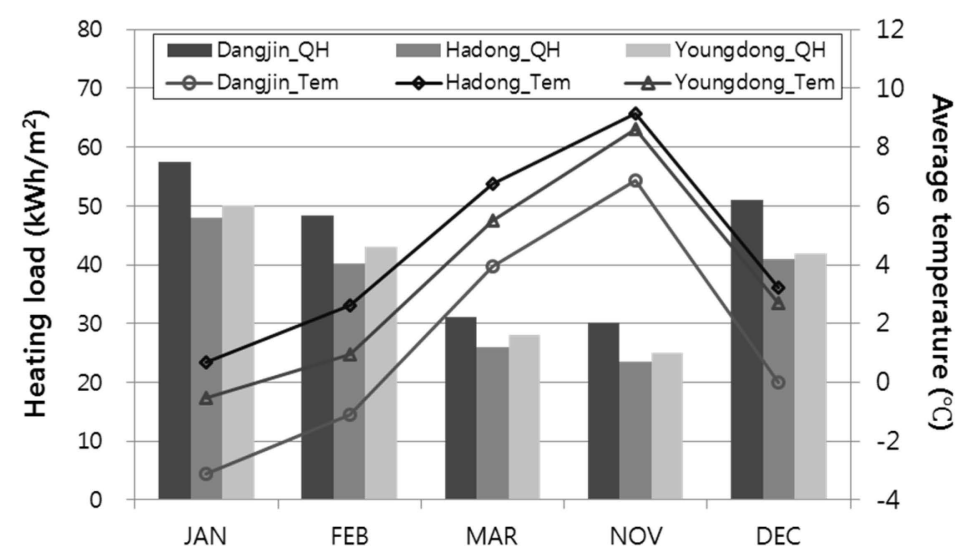

Figure 5. Heating load and average temperature of each case area. 


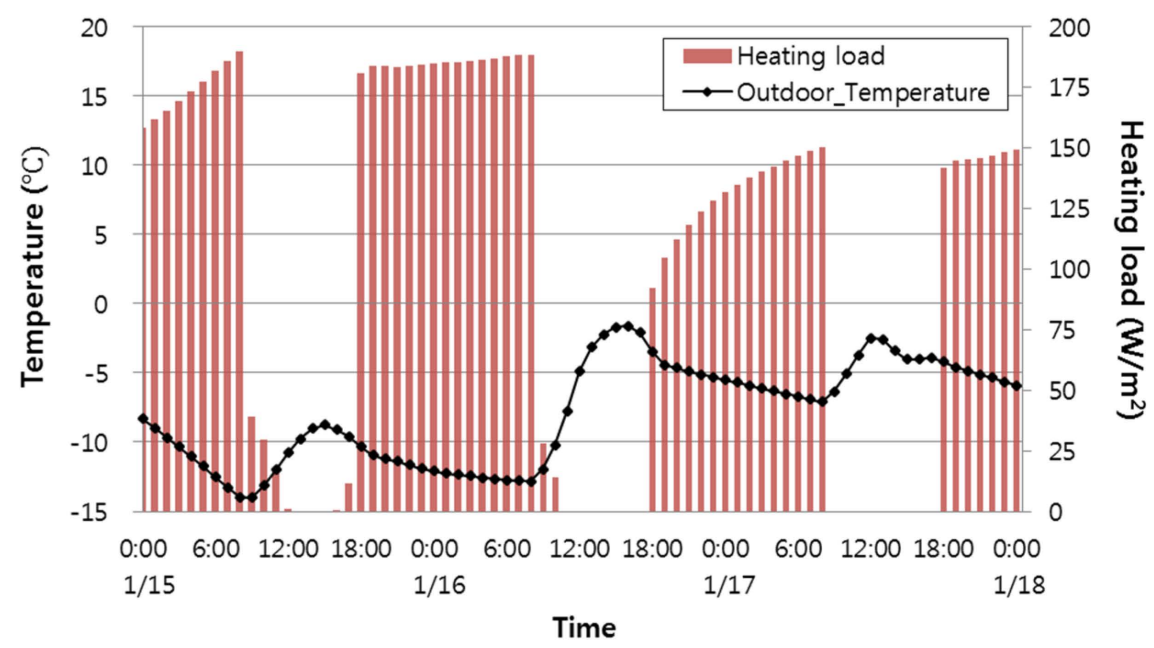

Figure 6. Simulation results of the representative three days in Dangin.

\subsection{Outlet Fluid Temperature Analysis}

Figure 7 show the outlet fluid temperature of each case study area according to distance. As mentioned above, the heat losses of the pipeline are influenced by the regional ground temperatures, causing different outlet fluid temperatures. The results show that the greatest temperature drop in each distance is in Youngdong and the smallest temperature drop is in Hadong.

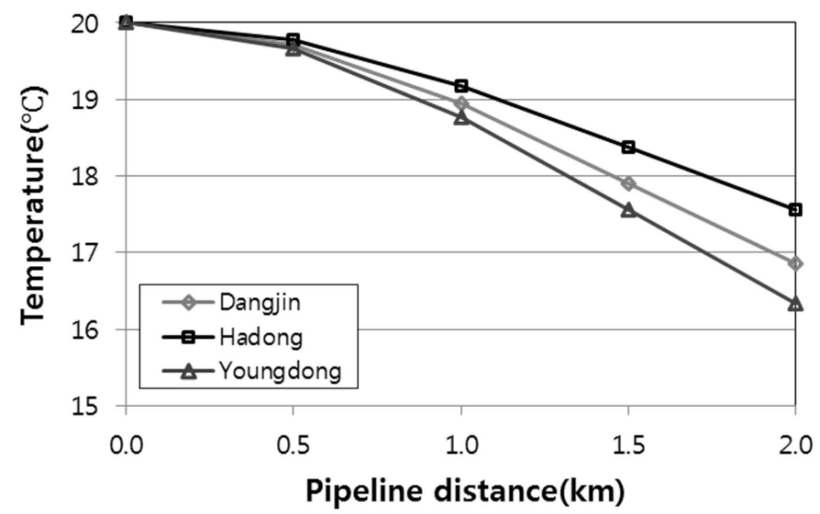

Figure 7. Outlet fluid temperature of each case study area by distance.

This means that the regional ground temperature influences on the temperature drop. The ground temperature is the lowest in Youngdong, and has the largest temperature difference from heat source fluid. Therefore, the case in Youngdong generates the greatest heat loss from pipelines. In addition, the distance from the heat source point to the horticultural land was taken into account. In the case of Dangin, the fluid temperature drops by $2.1^{\circ} \mathrm{C}$, so that the outlet fluid temperature is determined to be $17.9{ }^{\circ} \mathrm{C}$ since the distance is $1.5 \mathrm{~km}$ from the heat source point to the horticultural area. In the case of Hadong, the distance is $2 \mathrm{~km}$ from the heat source point so that the outlet fluid temperature is determined to be $17.6{ }^{\circ} \mathrm{C}$ and the temperature drops $2.4{ }^{\circ} \mathrm{C}$. In Youngdong, the temperature drops $0.3^{\circ} \mathrm{C}$ and the outlet fluid temperature is determined to be $19.7^{\circ} \mathrm{C}$ due to the distance of $0.5 \mathrm{~km}$ from heat source point to the horticultural area. Moreover, it was considered that both the regional ground temperature and the distance of each case study area to the plant. Although the temperature difference from the plant to the horticulture area was the largest in Youngdong, the distance from the power plant to the horticultural area was the shortest, so it could have the highest outlet fluid temperature. In addition, in the case of Hadong, the ground temperature was the highest so that the heat loss of the 
pipeline was the lowest. However, it was found that the outlet fluid temperature was the lowest since the distance from the power plant to the horticultural area was the farthest among them. Either way, the results show that the heat loss with temperature drop was low in general, since both the diameter and flow rate of the pipe are large.

\subsection{Energy Consumption Analysis}

The energy consumption of the horticultural areas was calculated from the heating energy consumption for the greenhouses and the consumption of pumping energy needed for the heat source flow, as shown in Table 5 and Figure 8.

Table 5. Heating and pumping energy consumption (kWh/ha).

\begin{tabular}{ccc}
\hline Location & Heating Energy Consumption & Pumping Energy Consumption \\
\hline Dangjin & 605,556 & 32,589 \\
Hadong & 497,222 & 35,566 \\
Youngdong & 522,222 & 15,232 \\
\hline
\end{tabular}
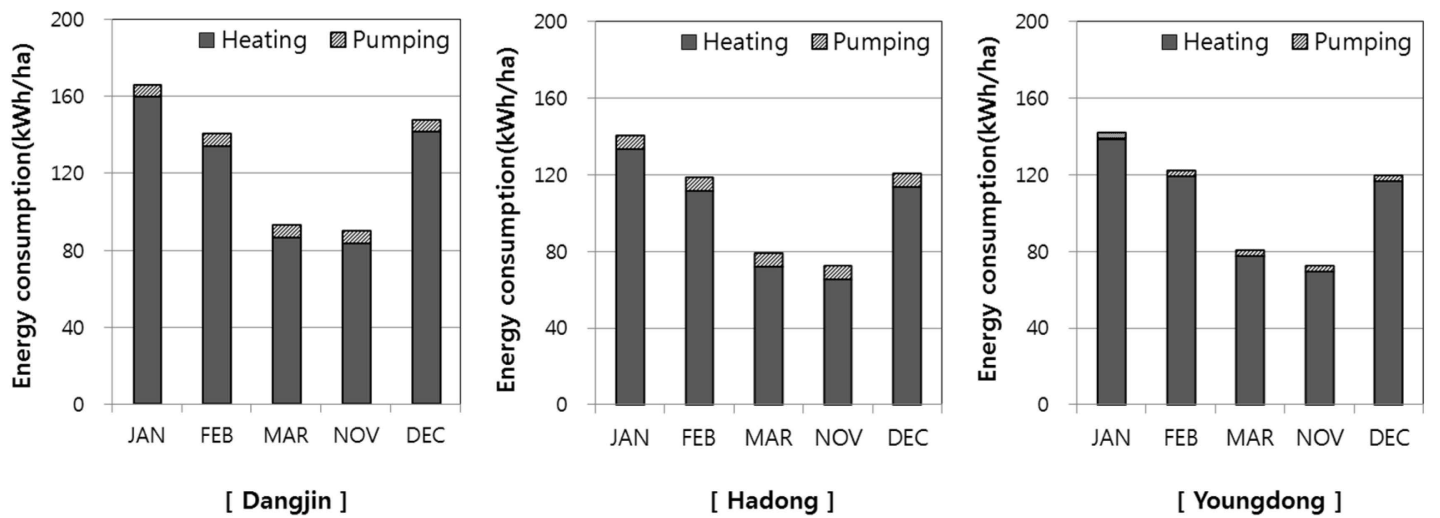

Figure 8. Heating and pumping energy consumption.

The annual heating energy consumed per hectare was determined to be 605,556 kWh in Dangjin, $497,222 \mathrm{kWh}$ in Hadong, and 522,222 kWh in Youngdong. As shown in Figure 8, a similar pattern was observed to that of the analysis result of the heating load by region. The annual pumping energy consumption per hectare was determined to be 32,589 kWh in Dangjin, 35,566 kWh in Hadong, and $15,232 \mathrm{kWh}$ in Youngdong. As a result, it was observed that a correlation with the distance from each heat source generation point to the greenhouse. In the case of Hadong, the distance from the power plant to the greenhouse is the farthest among the cases. In other words, it needs more pumping power compared with other cases. In the case of Youngdong, the distance is the nearest from the power plant to the greenhouse, which needs less pumping power. Overall, the pumping energy consumption is less than the heating energy consumption, so the pumping energy consumption does not have a significant influence on total energy consumption.

\subsection{Horticulture Scale Analysis}

In this section, the feasibility of the suggested size of the horticultural area was examined when utilizing power plant waste heat. In this regard, the potential size of horticultural area was calculated based on the peak heating load and thermal supply, as shown in Table 6. The hourly peak demand data was calculated by using dynamic energy simulation. As for determining the thermal power supply, it was referred to the previous studies $[6,12,21]$. In most previous studies, it was found that it is difficult to specify the hourly thermal energy figures from power plant. Therefore, they used annual average thermal power figures to calculate the size of horticulture. According to the previous studies, waste 
water with a stable temperature can be acquired annually from power plant. As to the flow rate of the waste water, since the power plant generates constant electric power annually, the thermal power can be supplied at a stable flow rate. Hence, the average thermal supply was utilized to calculate the size of the possible horticulture area. As a result, it is possible to construct 1279 ha of horticultural area in Dangjin, 1683 ha of horticultural area in Hadong and 159 ha of horticulture area in Youngdong by using waste heat energy. In terms of the peak energy needs of each region, Dangjin is the highest, followed by Hadong and Youngdong, although the power plant in Hadong can supply the largest thermal energy, followed by Dangjin and Youngdong. Hence, the results indicate that Youngdong provides the smallest size of horticultural area as it can supply the lowest energy. However, the largest scale of horticulture area can be created in Hadong as it has the largest energy supplies and the lowest peak demand for greenhouses. Either way, the results indicate that the assumed horticulture areas in the case study area are feasible.

Table 6. Potential size of horticulture area.

\begin{tabular}{cccc}
\hline Location & $\begin{array}{c}\text { Average Thermal } \\
\text { Supply (Gcal/h) }\end{array}$ & $\begin{array}{c}\text { Peak Heating Load } \\
\text { (Mcal/hah) }\end{array}$ & Horticulture Scale (ha) \\
\hline Dangjin & 2083 & 1629 & 1279 \\
Hadong & 2388 & 1419 & 1683 \\
Youngdong & 240 & 1513 & 159 \\
\hline
\end{tabular}

\section{Life Cycle Cost Analysis}

\subsection{Outline of Economic Analysis}

Economic analysis was carried out by calculating the initial investment costs and annual operation costs. As noted above, the area of construction was assumed to differ between cases. Hence, the unit costs of the suggested waste heat energy system were examined to compare with the conventional diesel boiler system. Then, Life Cycle Cost (LCC) analysis was conducted and the payback period was analyzed considering the construction area. Prior to analysis, the economic analysis condition is as follows.

For a conventional boiler system, the fuel consumed is diesel as it is widely used for horticulture. In addition, it was assumed that the diesel heating value is $9050 \mathrm{kcal} / \mathrm{L}$ and the boiler efficiency is $82 \%$ [24]. Table 7 shows the investment costs of each energy system. The standard income survey of the Korean agriculture promotion agency was referred to for the initial investment cost of the conventional diesel boiler [30]. The installation cost of the system using power plant waste heat was 1 billion won per hectare, according to Korean rural corporation and the costing was referred to the estimate which received from the construction company [12]. Figure 9 indicates the percentage of each system takes in total cost. Furthermore, $80 \%$ of the system installation cost using waste heat was supported by the Korean government. The installation cost of the heat transfer pipe was determined using the following Equation (5) [28]:

$$
C p p=32000+213000 \times D
$$

where, $C_{p p}$ : the pipeline installation cost (won/m), $D$ : the media pipe diameter $(\mathrm{m})$.

Table 8 shows the operation unit costs of each energy source used in the heating system. The diesel unit price is 605 won/L as a tax-free price on April 2015 [31]. The electricity costs for the pumping power and heat pump operation were sourced from the agricultural electricity unit cost of a Korea electric power corporation [32]. 


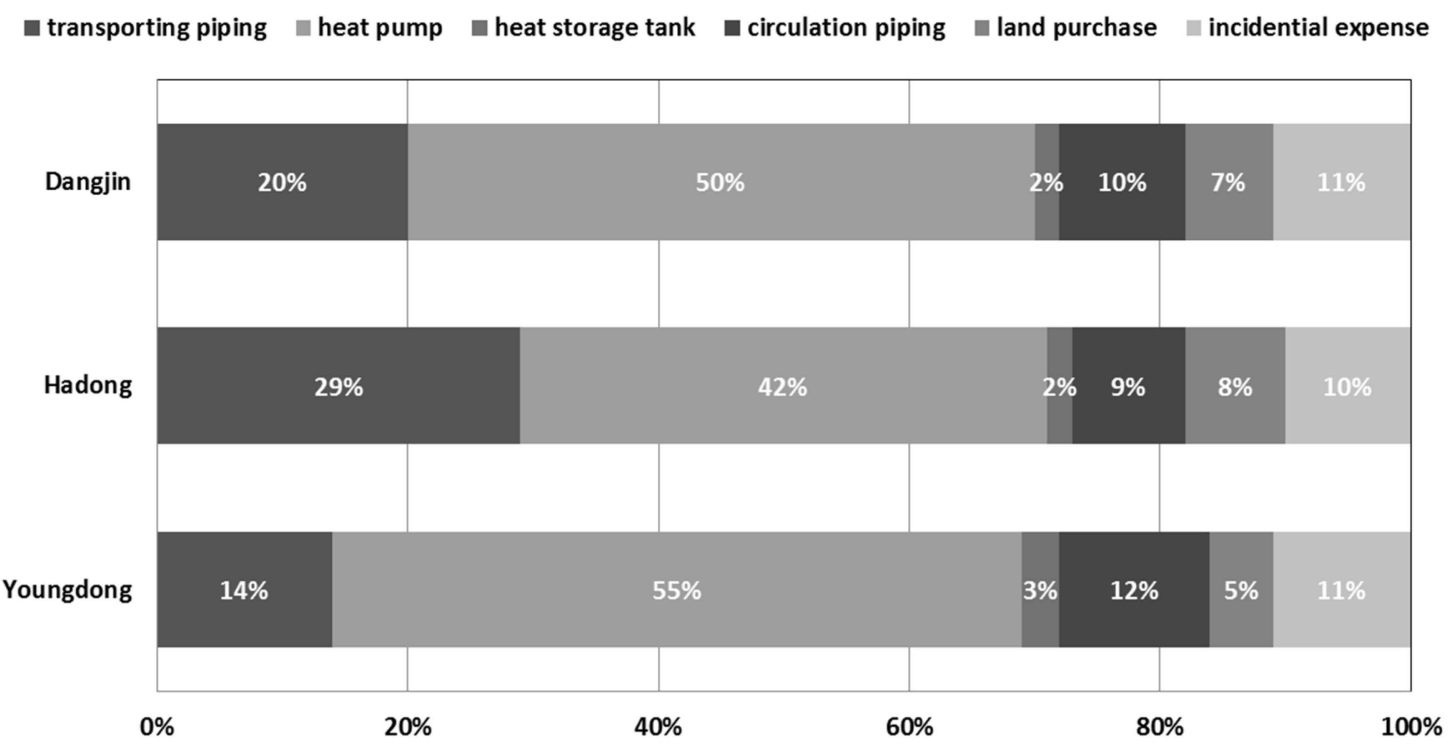

Figure 9. Percentage of each system in investment costs.

Table 7. Investment costs of each energy system.

\begin{tabular}{ccc}
\hline Fuel & System & Investment Cost (Won/ha) \\
\hline Diesel & Boiler & $3,600,000$ \\
Thermal effluent & Heat pump & $1,000,000,000$ \\
\hline
\end{tabular}

Table 8. Operation costs of each energy source.

\begin{tabular}{ccc}
\hline Fuel & Price & Unit \\
\hline $\begin{array}{c}\text { Tax free diesel } \\
\begin{array}{c}\text { Agricultural } \\
\text { electricity }\end{array}\end{array}$ & 605 & Won $/ \mathrm{L}$ \\
\hline
\end{tabular}

In addition, in order to examine the LCC and payback period, the present value method was applied and it was assumed that the discount rate is $3.4 \%$ and the analysis period is set to be 10 years. Equation (6) is used to calculate the non-repetitive cost and Equation (7) is used for the repetitive cost. The total present value is calculated by Equation (8):

$$
\begin{gathered}
P_{F}=\frac{F}{(1+i)^{n}} \\
P_{A}=\frac{A[(1+i)-1]}{i(1+i)^{n}} \\
P=P_{F}+P_{A}
\end{gathered}
$$

where, $P_{F}$ : the present value of future cash, $P_{A}$ : capitalization factor of annuity, $F$ : cost incurred after $\mathrm{n}$ years, $A$ : annual cost and $i$ : discount value.

\subsection{Operation Cost}

Tables 9 and 10 indicate the diesel and electricity consumption and costs. The operating costs were calculated based on the cost of the fuel consumed by each energy system. When using the boiler system, the diesel consumption was determined to be 253,194 L per hectare in Dangjin with a cost of $154,195,122$ won. In Hadong, the amount of diesel consumed was 207,898 L and the estimated cost is 
$126,609,756$ won. In Youngdong, the diesel consumption cost was determined to be 132,975,610 won with $218,351 \mathrm{~L}$ of diesel consumed per hectare. When using power plant waste heat, $638,144 \mathrm{kWh}$ of electricity was used in Dangjin and the cost was determined to be 26,530,290 won. In Hadong, 532,788 $\mathrm{kWh}$ of electricity was consumed and the estimated cost was 21,931,009 won. In the case of Youngdong, the electricity consumption was 537,455 kWh and the cost was 23,072,293 won. Comparing each energy system according to region, it was confirmed that the operation cost of utilizing power plant waste heat reduces the cost by about 83\% compared to using boiler diesel, as shown in Figure 10.

Table 9. Diesel consumption and price in each case.

\begin{tabular}{ccc}
\hline Location & Diesel Consumption (L) & Diesel Price (Won) \\
\hline Dangjin & 253,194 & $154,195,122$ \\
Hadong & 207,898 & $126,609,756$ \\
Youngdong & 218,351 & $132,975,610$ \\
\hline
\end{tabular}

Table 10. Electricity consumption and price in each case.

\begin{tabular}{ccc}
\hline Location & Electricity Consumption (kWh) & Electricity Price (Won) \\
\hline Dangjin & 638,144 & $26,530,290$ \\
Hadong & 532,788 & $21,931,009$ \\
Youngdong & 537,455 & $23,072,293$ \\
\hline
\end{tabular}
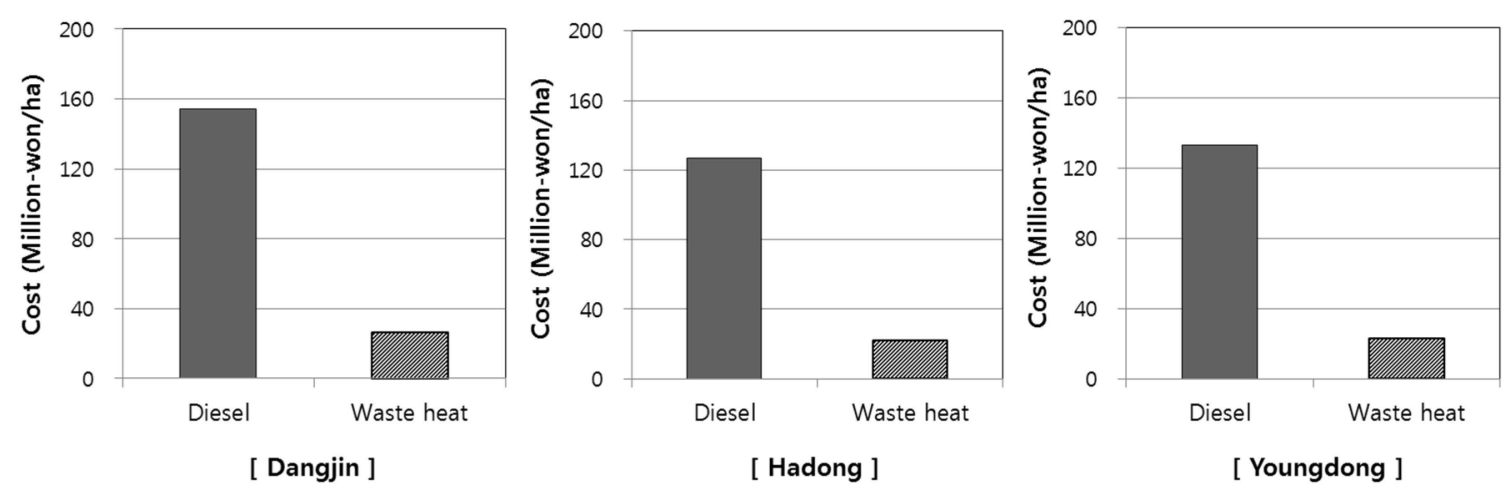

Figure 10. Comparison of operation costs in each case.

\subsection{Payback Period Analysis}

LCC comparison and payback period analysis were conducted between the heat pump system using power plant waste heat and the conventional diesel boiler. Table 11 and Figure 11 indicate the LCC and payback period analysis. The investment cost using the waste heat system is considerably more expensive than for a conventional system, even though a government assistance of $80 \%$ was applied. However, the annual operating costs of a conventional system are about $83 \%$ greater than that of a waste heat system. Therefore, the higher initial investment cost incurred by utilizing power plant waste heat can be recovered annually from the reduced annual operating costs. From Figure 11, it was found that the feasibility was demonstrated by the payback period. In the case of Dangjin, the payback period of using waste heat system was confirmed to be two years by reducing the annual operation cost by 12,935,769 won. In the case of Hadong, the payback period of using the waste heat system was three years by an annual operation cost reduction of 7,886,157 won. In the case of the Youngdong power plant, the payback period of using a waste heat system was determined to be two years by reducing annual operating costs by 10,626,900 won. Compared with the existing system, it was confirmed that there is sufficient economic value in using the waste heat pump system. 
Table 11. Cost analysis (Thousand-won).

\begin{tabular}{cccc}
\hline & Dangjin & Hadong & Youngdong \\
\hline Initial cost & $100,000,473$ & $52,000,631$ & $13,000,158$ \\
Operation cost & $13,265,145$ & $5,702,062$ & $1,499,699$ \\
Annual cost reduction & $63,832,416$ & $27,216,474$ & $7,143,716$ \\
Payback period & 2 & 3 & 2 \\
\hline
\end{tabular}

Furthermore, if not subsidized situation, and it was confirmed that the initial cost is determined to be 500,002,368 thousand-won in Dangjin, 260,003,157 thousand-won in Hadong and $65,000,789$ thousand-won in Youngdong. As a result, the payback period was 10 years in Dangjin, 12 years in Hadong, and 12 years in Youngdong. Therefore, it is necessary to get subsidy in order to be economical in 10 years.

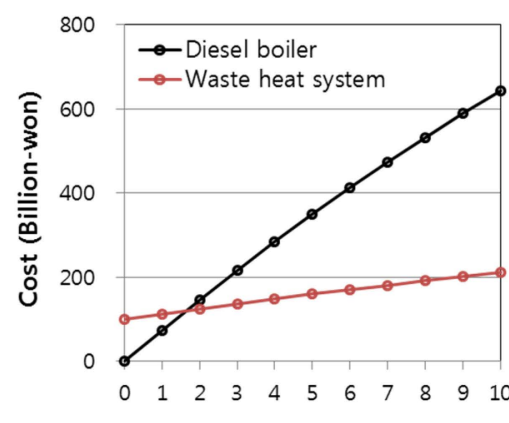

[ Dangjin ]

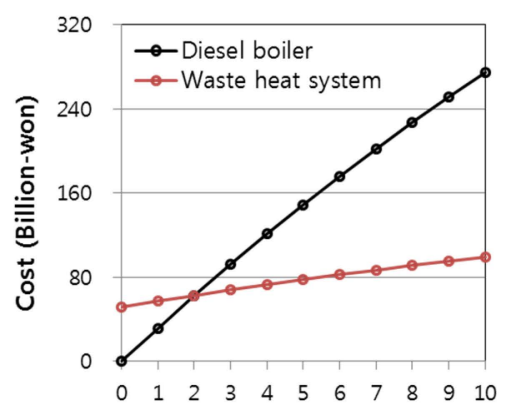

[ Hadong ]

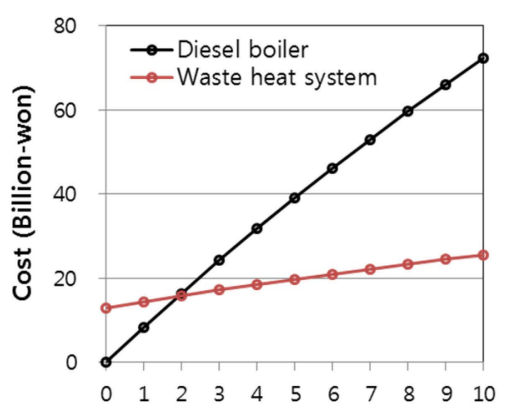

[ Youngdong ]

Figure 11. LCC comparative and payback period analysis.

\section{Conclusions}

In this study, the feasibility of using power plant waste heat for large-scale protected horticulture was estimated to determine an efficient and economic energy source system. In this paper, the energy reserves of waste heat discharged from power plants were calculated in Korea. The heating load and the energy consumption were also analyzed in three different areas using a dynamic simulation. Finally, the potential of the suggested system was estimated comparing with the conventional system. The results are summarized as follows.

- It was confirmed that the discharged thermal effluent capacity differed between power plants located on each coast of Korea. According to the survey, power plants were located mainly on the West and South coast and the energy reserves of the nuclear power plants were higher than those of thermal power plants. Moreover, the energy reserves were a key variable to examine the applicability of waste heat as energy source compared with the heating energy consumption.

- According to the heating load analysis, the largest load was indicated in Dangjin, where the weather conditions are the coldest, followed by Youngdong and Hadong. From this result, there is a correlation between each regional weather condition and heating load. On the other hand, an increased heating load means increased heating energy consumption.

- Comparing the energy reserves and heating energy consumption, it was confirmed that there was sufficient amount of reserves to supply energy to the assumed areas in this paper. In Dangjin, by utilizing about $20 \%$ of energy reserves of the Dangjin thermal power plant, it was assumed that an area of 500 ha could be used. In Hadong, the assumed area is 260 ha, utilizing about $7.4 \%$ of the energy reserves of the Hadong thermal power plant. In Youngdong, an assumed area of 65 ha can be constructed when utilizing about 19\% of the energy reserves of the Youngdong thermal power plant. 
- Based on the energy analysis for each case, a comparative analysis with a conventional energy supply system was carried out. The initial investment can be recovered from the approximately $83 \%$ reduction the annual operating costs. It was confirmed that the investment could be recovered after about two years in Dangjin, three years in Hadong, and two years in Youngdong.

Acknowledgments: This work was carried out with the support of "Cooperative Research Program for Agriculture Science \& Technology Development (Project title: Development of Optimal District Energy and Operation System for Large-scale Horticulture Facility Application, Project No. PJ010021022015)" Rural Development Administration, Republic of Korea. This research was supported by Basic Science Research Program through the National Research Foundation of Korea (NRF) funded by the Ministry of Education, Science and Technology (No. 2015R 1D 1A3A01020132).

Author Contributions: All authors contributed equally to this work. All authors designed the simulations, discussed the results and implications and commented on the manuscript at all stages.

Conflicts of Interest: The authors declare no conflict of interest.

\section{References}

1. Kim, Y.J. Trend of clean energy industry and the prospect of its expandability to agricultural sector. J. Korea Rural Econ. Inst. (KREI) 2011, R635, 1-284.

2. Kim, Y.J.; Park, H.T.; Han, H.S.; Moon, D.H. Management analysis of cooling-heating system and thermal type in the major horticultural crops. J. Korea Rural Econ. Inst. (KREI) 2014, D373, 1-82.

3. Yu, M.G.; Nam, Y.J.; Lee, G.H. Design method of heat storage type ground source heat pump system considering energy load pattern of greenhouse. J. Korea Inst. Ecol. Archit. Environ. (KIEAE) 2015, 15, 57-63. [CrossRef]

4. Park, M.L.; Ryoo, Y.S.; Kim, J.W.; Lee, Y.U.; Bae, S.D.; Chae, K.B. A study on analysis of reserves and available capacity of unutilized energy in rural community. J. Korean Sol. Energy Soc. (KSES) 2014, 34, 19-25. [CrossRef]

5. Park, J.T.; Chang, K.C. An investigation on quantity of unused energy using temperature difference energy as heat source and its availability. J. Korea Soc. Energy Eng. (KOSEE) 2002, 11, 106-113.

6. Hyun, I.T.; Lee, J.H.; Yoon, Y.B.; Lee, K.H.; Nam, Y.J. The potential and utilization of unused energy source for large-scale horticulture facility applications under Korean climatic conditions. Energies 2014, 7, 4781-4801. [CrossRef]

7. Chau, J.; Sowlati, T.; Sokhansanj, S.; Preto, F.; Melin, S.; Bi, X. Economic sensitivity of wood biomass utilization for greenhouse heating application. Appl. Energy 2009, 86, 616-621. [CrossRef]

8. Benli, H. Energetic performance analysis of a ground-source heat pump system with latent heat storage for a greenhouse heating. Energy Convers. Manag. 2011, 52, 581-589. [CrossRef]

9. Benli, H.; Durmus, A. Evaluation of ground source heat pump combined latent heat storage system performance in greenhouse heating. Energy Build. 2009, 41, 220-228. [CrossRef]

10. Esen, M.; Yuksel, T. Experimental evaluation of using various renewable energy sources for heating a greenhouse. Energy Build. 2013, 65, 340-351. [CrossRef]

11. Cho, J.H.; Kim, D.Y.; Lee, J.S. Directions for developing green aquaculture using thermal effluent from power plant. J. Korea Marit. Inst. 2010, 5, 1-141.

12. Heo, T.H. On the application of the heat pump system to facility horticulture, using hot waste water from power plants. Ph.D. Dissertation, Jeju National University, Jeju, Korea, 2012.

13. Dalla Rosa, A.; Boulter, R.; Church, K.; Svendsen, S. District heating (DH) network design and operation toward a system-wide methodology for optimizing renewable energy solutions (SMORES) in Canada: A case study. Energy 2012, 45, 960-974. [CrossRef]

14. Dalla Rosa, A.; Li, H.; Svendsen, S. Method for optimal design of pipes for low-energy district heating, with focus on heat losses. Energy 2011, 36, 2407-2418. [CrossRef]

15. Tol, H.I.; Svendsen, S. A comparative study on substation types and network layouts in connection with low-energy district heating systems. Energy Convers. Manag. 2012, 64, 551-561. [CrossRef]

16. Li, X.-L.; Duanmu, L.; Shu, H.-W. Optimal design of district heating and cooling pipe network of seawater-source heat pump. Energy Build. 2010, 42, 100-104. [CrossRef]

17. Yildirim, N.; Toksoy, M.; Gokcen, G. Piping network design of geothermal district heating systems: Case study for a university campus. Energy 2010, 35, 3256-3262. [CrossRef] 
18. Ivner, J.; Viklund, S.B. Effect of the use of industrial excess heat in district heating on greenhouse gas emissions: A systems perspective. Resources. Conserv. Recycl. 2015, 100, 81-87. [CrossRef]

19. Michon, X. Agricultural use of waste heat from condensing circuits of French nuclear power stations [warm water, greenhouses and plastic tunnels, waste water, Saint-Laurent des Eaux, Dampierre-en-Burly, Buguey, Chinon, Le Blayais]. J. Int. Inf. Syst. Agric. Sci. Technol. (AGRIS) 1986, 71, 6.

20. Lee, J.H.; Yoon, Y.B.; Hyun, I.T.; Lee, K.H. The Korean effect of pip network materials and distance on unused energy source system performance for large-scale horticulture facilities. J. Korea Inst. Ecol. Archit. Environ. (KIEAE) 2014, 14, 119-125.

21. Lee, J.H.; Hyun, I.T.; Yoon, Y.B.; Lee, K.H.; Nam, Y.J. Energetic and economic assessment of pipe network effects on unused energy source system performance in large-scale horticulture facilities. Energies 2015, 8, 3328-3350. [CrossRef]

22. Ryou, Y.S.; Kang, Y.K.; Jang, J.K.; Kim, J.G.; Kang, G.C. Heat exchanger design of a heat pump system using the heated effluent of thermal power generation plant as a heat source for greenhouse heating. J. Korean Soc. Bio Environ. Control 2012, 21, 372-378. [CrossRef]

23. Electric Power Statistics Information System (EPSIS). Available online: https:/ /epsis.kpx.or.kr (accessed on 16 August 2015).

24. Yu, M.G.; Cho, J.H.; Nam, Y.J. Feasibility study of the energy supply system for horticulture facility using dynamic energy simulation. J. Korea Inst. Ecol. Archit. Environ. (KIEAE) 2015, 15, 105-111. [CrossRef]

25. Takuya, T.; Tsuyoshi, F.; Liang, D.; Minoru, F.; Makoto, O. Feasibility assessment of the use of power plant-sourced waste heat for plant factory heating considering spatial configuration. J. Clean. Prod. 2014, 81, 60-69.

26. Korean Rural Development Administration. New Agricultural Energy-Saving Technology for the Improvement of Farm Management Balance; Korean Rural Development Administration (RDA): Jeonju, Korea, 2010.

27. Korean Institute of Energy Research (KIER). Available online: http://kredc.kier.re.kr/kier (accessed on 17 August 2015).

28. Park, J.C. Design direction and standard model of korean-type glasshouse. J. Korean Soc. Bio Environ. Control 1993, 6, 16-30.

29. DAESUNGHEATPUMP. Available online: http://www.dsheatpump.co.kr (accessed on 17 August 2015).

30. Korean Rural Development Administration (RDA). Available online: http://www.rda.go.kr (accessed on 17 August 2015).

31. Korea National Oil Corporation (KNOC). Available online: http://www.opinet.co.kr (accessed on 17 August 2015).

32. Korean Electric Power Corporation (KEPCO). Available online: http:/ / cyber.kepco.co.kr (accessed on 15 July 2014). 